\title{
ANÁLISE DA COMPOSTAGEM DE LODO DE TRATAMENTO DE EFLUENTES DA INDÚSTRIA DE PESCADO COM DIFERENTES MATERIAIS ESTRUTURANTES
}

Carolina da Silva Gonçalves - carolzitasg@ gmail.com

Universidade Federal de Pelotas

Matheus Francisco da Paz - matheusfdapaz@ hotmail.com

Universidade Federal de Pelotas

Mateus Torres Nazari - nazari.eas@gmail.com

Universidade Federal de Pelotas

Maurízio Silveira Quadro - mausq@ hotmail.com

Universidade Federal de Pelotas

Luciara Bilhalva Corrêa - luciarabc@gmail.com

Universidade Federal de Pelotas

Érico Kunde Corrêa - ericokundecorrea@yahoo.com.br

Universidade Federal de Pelotas 


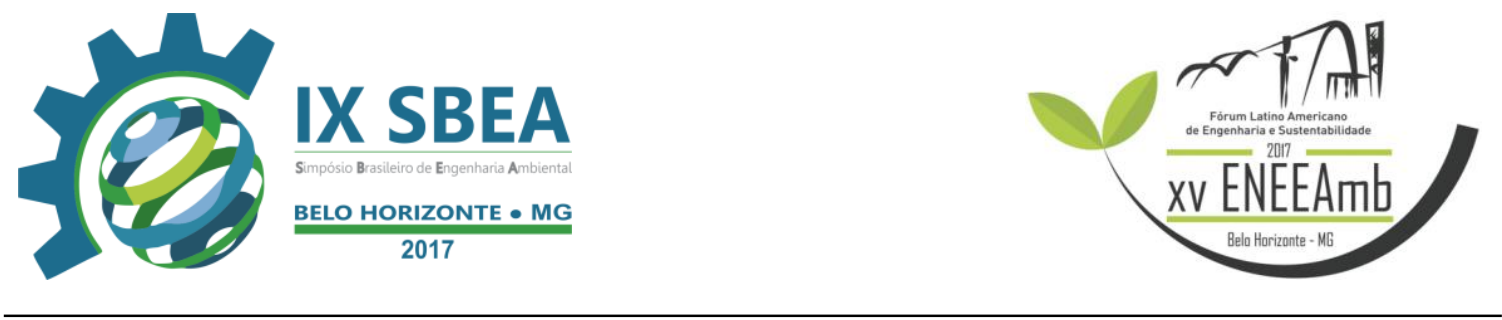

\section{RESUMO}

Ferramenta eficiente de reciclo da matéria orgânica, a compostagem possui mecanismo é essencialmente aeróbio, sendo necessário resíduos estruturantes para promover o aporte de oxigênio necessário. Portanto, o objetivo deste estudo foi a avaliação de diferentes materiais estruturantes na compostagem de lodo de estação de tratamento de efluentes da indústria de pescado. Foram utilizadas composteiras de 100L com 1/2 (volume/volume) de lodo de estação de tratamento de efluentes da indústria de pescado, seguido de diferentes tratamentos: tratamento com casca de arroz (TCA), tratamento com casca de pinus (TCP) e tratamento com serragem (TSE), com 10\% de espaço livre para facilitar o revolvimento. O período de compostagem se deu por 105 dias com revolvimento semanal. A temperatura das composteiras foi medida diariamente. Quinzenalmente, alíquotas de aproximadamente 30 gramas foram retiradas para análises de condutividade elétrica. $\mathrm{O}$ TCA apresentou maior temperatura em comparação aos demais materiais estruturantes, bem como maior condutividade elétrica. Dentre os materiais estruturantes estudados, a casca de arroz demonstrou maior potencial de degradabilidade do lodo de estação de tratamento de efluentes da indústria de pescado por compostagem, sendo o mais indicado para seu uso em associação ao lodo de estação de tratamento da indústria de pescado.

Palavras-chave: Casca de Pinus, Casca de Arroz, Serragem.

\section{INTRODUÇÃO/OBJETIVO}

A compostagem caracteriza-se como um dos métodos mais eficientes para reciclagem de matéria orgânica. É um processo no qual microrganismos aeróbios mineralizam substratos tornando-os aptos a incorporação ao solo e reduzindo seu impacto sobre o meio ambiente (ZHANG et al., 2012).

A reciclagem tanto de materiais não biodegradáveis quanto de materiais passíveis de biodegradação costumam ser menos dispendiosos do que a destinação final em aterros sanitários, que necessitam de maiores preocupações e em um prazo maior (FERREIRA et al., 2014).

Ao tratar-se da compostagem, diversas particularidades devem ser levadas em consideração para que o processo seja eficaz. Dentre esses requisitos, o mais importante recai sobre a presença de oxigênio no processo. Com a ausência deste, as degradações 
ocorrem de forma anaeróbia, gerando mau cheiro com produção de compostos voláteis de baixo peso molecular, lentidão no processo de degradação, atração de moscas e outros insetos (GUO et al., 2012).

O processo de degradação aeróbia pelos microrganismos, de forma simplificada, consiste no uso de carboidratos como fonte de energia, tendo como receptor de elétrons no final da cadeia transportadora o oxigênio, gerando gás carbônico pelo processo de descarboxilação dos carboidratos e água (SHARMA et al., 1997 \& NELSON; COX, 2014).

Com a ausência do oxigênio como receptor, outros compostos adquirem esses elétrons e há geração de ácidos orgânicos de baixo peso molecular, como o ácido lático e ácido acético e muitas vezes produção de diversos compostos voláteis, como metano e butano, que podem causar mal cheiro e diminuir o $\mathrm{pH}$ do composto, ambos fatores negativos para o processo de compostagem, demonstrando assim a importância do aporte de oxigênio através da aeração (NELSON; COX, 2014).

Para assegurar uma quantidade de oxigênio necessária para o crescimento e atividade de microrganismos aeróbios, é necessária a presença de materiais estruturantes, normalmente ricos em carbono, que criam espaços intersticiais na pilha do composto, facilitando a entrada de ar (GUO et al. 2012 \& JOLANUN; TOWPRAYOON, 2010).

A granulometria do material é fator decisivo, principalmente em relação ao processo de aeração, já que materiais muito compactados podem ocasionar em formação de anaerobiose e produtos advindos desta condição (CARMONA et al., 2003), ao passo que uma granulometria muito grande pode afetar o processo de degradação, já que dificulta o acesso por parte dos microrganismos, resultando em um tempo prolongado de compostagem ou até mesmo degradação parcial do material (BERNAL et al., 2009).

Para que isso não ocorra, é de vital importância a escolha do resíduo estruturante, pois além de fonte de carbono, ele age intimamente na granulometria da massa a ser compostada, promovendo espaços intersticiais que facilitam a passagem de ar, auxiliando na degradação aeróbia desse material. Dentre os materiais estruturantes comumente utilizados para o uso na compostagem, cabe citar: casca de arroz, serragem, maravalha, restos de poda, palha, entre outros (ROCA-PÉREZ et al. 2009; KAUSAR, et al., 2011)

A casca de arroz é um resíduo abundante, já que em parâmetros mundiais, o arroz 


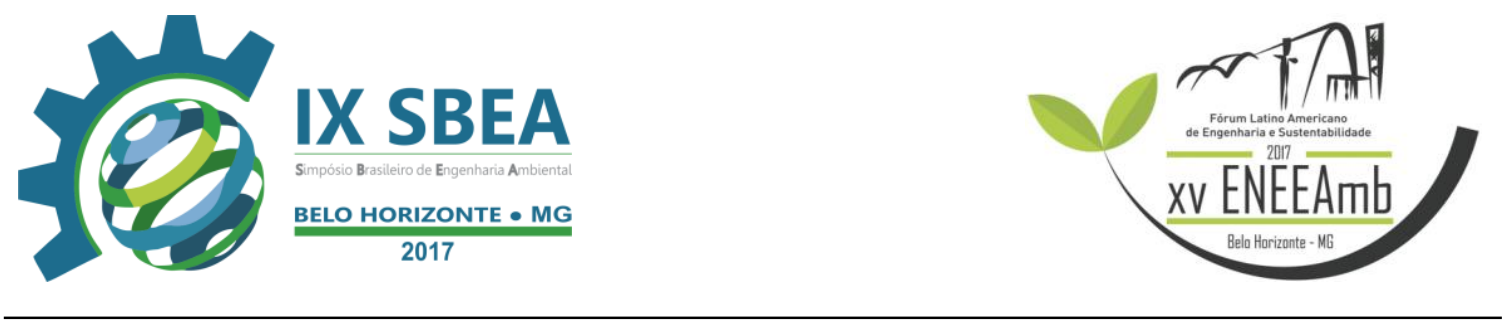

representa o commoditie mais produzido no mundo, ultrapassando 696 milhões de toneladas em 2010 (FAO, 2010). O Brasil produziu na safra de 2014/2015 cerca de 12,399 milhões de toneladas, onde o estado do Rio Grande do Sul foi responsável por $68,07 \%$ da produção do país (CONAB, 2015). Considerando que a casca representa em torno de $20 \%$ do peso do grão (LUDUEÑA et al., 2011), apenas no estado do Rio Grande do Sul se produziu, no ano de 2011, cerca de 2,48 milhões de toneladas de casca de arroz, sendo interessante seu uso aplicado a região em questão.

Outro material estruturante que atende a estes requisitos é a serragem. A indústria florestal brasileira possui grandes efeitos multiplicadores para geração de emprego, geração de impostos, salários entre outros fatores socioeconômicos, superiores até a indústria automobilística (VALVERDE et al., 2003).

Semelhante à serragem, a casca de pinus também se caracteriza como um resíduo da indústria madeireira. Muitas vezes esta casca é utilizada para fins de queima e geração de energia, embora ambientalmente tal atividade possa ser regulamentada, seu uso na compostagem é mais indicado, considerando todas as variáveis dos impactos ambientais causados por essas atividades distintas (BRAND et al., 2002).

Portanto, este trabalho objetivou a comparação entre diferentes resíduos estruturantes na compostagem de lodo de estação de tratamento de efluentes da indústria de pescado.

\section{METODOLOGIA}

Foi utilizado composteiras de 100 litros segundo metodologia adaptada de Kapanen et al. (2013). Nestas composteiras foram dispostas na proporção de $1 / 2$ (volume/volume) de lodo de estação de tratamento de efluentes da indústria de pescado, seguido de diferentes tratamentos: tratamento com casca de arroz (TCA), tratamento com casca de pinus (TCP) e tratamento com serragem (TSE), com 10\% de espaço livre para facilitar o revolvimento. O processo de compostagem foi realizado durante 105 dias e operação unitária de revolvimento foi executada semanalmente, segundo metodologia proposta por El Fels et al. (2014). A temperatura das composteiras foi medida diariamente com auxílio de termômetro JProlab digital $\left(0,1^{\circ} \mathrm{C}\right)$. Quinzenalmente, alíquotas de 


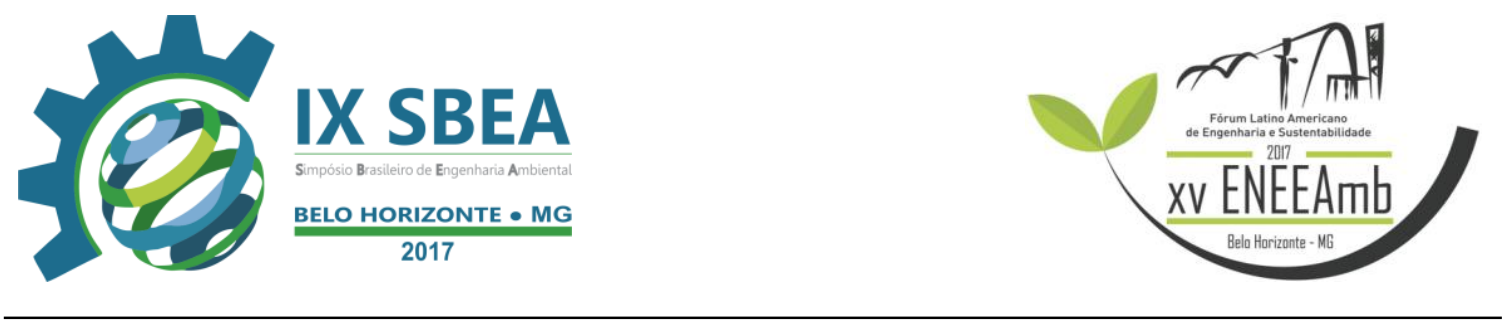

aproximadamente 30 gramas foram retiradas para análises de condutividade, realizada de acordo com Embrapa (1996).

O delineamento experimental deu-se em blocos $3^{2}$ completamente casualizados com três repetições, sendo o fator tratamento diferentes resíduos estruturantes. Os fatores resposta analisados foram o índice de germinação das sementes de pepino, alface e rabode-galo, carbono orgânico total, nitrogênio total, relação carbono nitrogênio, pH, condutividade, matéria mineral e umidade.

Foram identificados dados atípicos (outliers) e os dados obtidos tiveram sua normalidade analisada pelo teste de Shapiro-Wilk, a homocedasticidade das amostras pelo teste de Hartley e a independência dos resíduos por análise gráfica. As variáveis foram normalizadas e submetidas ao teste de variância pelo teste de Tukey $(\mathrm{p}<0,05)$.

\section{RESULTADOS E DISCUSSÃO}

Os resultados para temperatura dos compostos com diferentes resíduos estruturantes podem ser observados na Figura 1. 

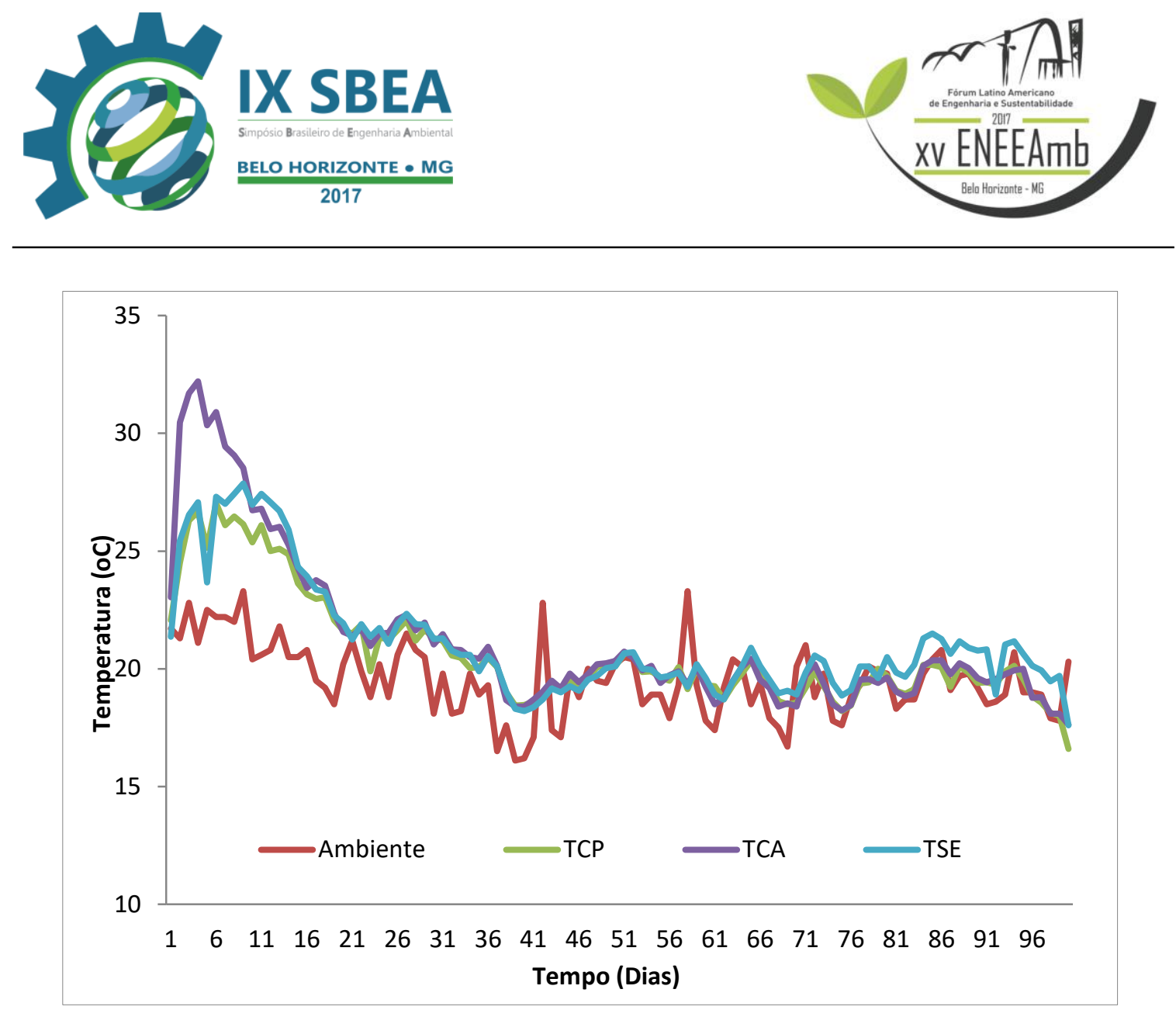

Figura 1 - Temperaturas diárias ao longo de 105 dias de compostos elaborados com lodo de estação de tratamento de pescado com diferentes materiais estruturantes e temperatura ambiente $(n=1260)$.

O TCA apresentou temperaturas superiores nos primeiros dias em comparação a outros materiais estrututante. Todas composteiras apresentaram temperatura superior a temperatura ambiente constatada. No entanto, nenhum dos compostos alcançou a fase termofílica, ou se o fez foi em um período não detectado pelo monitoramento.

Após o $11^{\circ}$ dia, as temperaturas dos compostos com diferentes materiais estruturantes continuavam superiores a temperatura ambiente, todavia, não havia mais distinção entre os tratamentos. A partir do $21^{\circ}$ dia, a temperatura ambiente se assemelhou na maioria dos pontos com a temperatura das composteiras.

Segundo Zhang; Sun (2016), independente do material estruturante, a compostagem apresenta diferentes fases em relação à temperatura, sendo detectada presença de fase termofílica após o início do processo. Resultados estes que diferem com os encontrados neste experimento.

Este resultado pode ser explicado devido a vários fatores, entre eles cabe citar: o tamanho da composteira, que pode ter contribuído para a dissipação rápida do calor 
da fase termófilica (LI; LU; HE, 2013). O acesso ao nitrogênio por parte de microrganismos, considerando os grumos formados pelo lodo no processo de prensagem de lodo de estação de tratamento de pescado, com necessidade de redução do tamanho de partícula; maior percentual de nitrogênio presente em compostos com elaboração de casca de arroz em comparação aos demais agentes estruturantes. Segundo Yañes; Alonso; Días (2009), um maior aporte de nitrogênio no começo da compostagem pode proporcionar uma fase termofílica mais avantajada, já que disponibiliza esse nutriente de forma abundante para a síntese de proteínas e aminoácidos para os microrganismos.

A condutividade elétrica $\left(\mu \mathrm{s} / \mathrm{cm}^{-1}\right)$ dos compostos estudados podem ser observados na Tabela 2 .

Tabela 1 - Condutividade elétrica $\left(\mu \mathrm{s} / \mathrm{cm}^{-1}\right)$ observados na compostagem de LEEP com diferentes materiais estruturantes $(n=216)$.

\begin{tabular}{|l|c|c|c|c|c|c|c|c|}
\hline Trat* & \multicolumn{7}{|c|}{ Tempo em dias } \\
\hline & 0 & 15 & 30 & 45 & 60 & 75 & 90 & 105 \\
\hline TCP & $318,3^{\mathrm{b}}$ & $549,4^{\mathrm{b}}$ & $419,0^{\mathrm{c}}$ & $559,2^{\mathrm{b}}$ & $650,43^{\mathrm{b}}$ & $518,0^{\mathrm{c}}$ & $424,1^{\mathrm{c}}$ & $588,1^{\mathrm{b}}$ \\
\hline TCA & $790,7^{\mathrm{a}}$ & $1093,3^{\mathrm{a}}$ & $1301,0^{\mathrm{a}}$ & $1430,7^{\mathrm{a}}$ & $1383,1^{\mathrm{a}}$ & $1389,7^{\mathrm{a}}$ & $1519,7^{\mathrm{a}}$ & $1149,7^{\mathrm{a}}$ \\
\hline TSE & $418,2^{\mathrm{b}}$ & $612,7^{\mathrm{bc}}$ & $714,2^{\mathrm{b}}$ & $785,7^{\mathrm{b}}$ & $831,6^{\mathrm{b}}$ & $858,27^{\mathrm{b}}$ & $761,1^{\mathrm{b}}$ & $832,4^{\mathrm{b}}$ \\
\hline
\end{tabular}

Letras diferentes na coluna diferem entre si pelo teste de Tukey $(\mathrm{p}<0,05)$.

*Trat=Tipo de Tratamento

Pode-se observar através da Tabela 5, que houve um aumento da condutividade elétrica dos materiais, com uma estababilização entre os dias 60 e 70. Esse comportamento é esperado, dado que conforme há um aumento da degradabilidade do composto, há um aumento da condutividade elétrica, indicado pela mineralização do resíduo orgânico (BERNAL; ALBURQUERQUE; MORAL, 2009). 


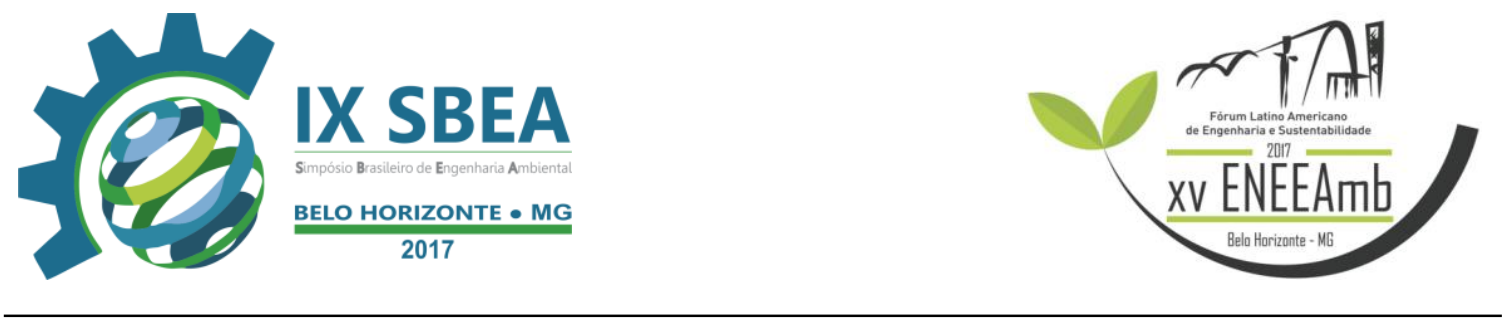

O TCA apresentou uma maior mineralização em comparação com os demais materiais estruturantes, apresentando valores finais de $1149,7 \mu \mathrm{s} / \mathrm{cm}^{3}$, com interação da variável tempo, apresentando uma regressão com equação 806,89 + 305,60x $35,39 x^{2}$ e $\mathrm{R}^{2}=89,97$ com $\mathrm{p}=4,87 \times 10^{-9}$, ao passo que a equação do TCP para regressão foi 434,55 +19,65x com $\mathrm{p}=0,09$ e $\mathrm{R}^{2}=19,79$ e para TSE a equação 555,11 +49,05x com $\mathrm{p}=3,35 \times 10^{-5}$ e $\mathrm{R}^{2}=66,26$.

\section{CONCLUSÕES/RECOMENDAÇÕES}

Dentre os materiais estruturantes estudados, a casca de arroz apresenta melhores resultados em comparação com os demais resíduos estudados, pois alcançou temperaturas superiores e resultou em maiores valores de condutividade, demonstrando assim maior potencial de degradabilidade do lodo de estação de tratamento de efluentes da indústria de pescado por compostagem, sendo o mais indicado para este material.

\section{REFERÊNCIAS BIBLIOGRÁFICAS}

BERNAL, M. P.; AlBURQUERQUE, J. A.; MORAL, R. Composting of animal manures and chemical criteria for compost maturity assessment. A review. Bioresource Technology, n. 100, p. 5444-5453, 2009.

BRAND, M. A.; MUÑIZ, G. I. B.; SILVA, D. A.; KLOCK, U. Caracterização do rendimento e quantificação dos resíduos gerados em serraria através de balanço de materiais. Revista Floresta, v. 32, n. 2, p. 247-259, 2002.

CARMONA, E.; ORDOVÁS, J. MORENO, M. T.; AVILÉS, M. Granulometric characterization and alteration during composting of industrial cork residue use as a growing medium. Hort Science, v. 38, n. 6, p. 1242-1246, 2003.

EL FELS, L.; ZAMAMA, M.; EL ASLI, A.; HAFIDI, M. Assessment of biotransformation of organic matter during co-composting of sewage sludgelignocellullosic waste by chemical, FTIR analyses, and phytotoxicity tests. International Biodeterioration \& Biodegradation, v. 87. p. 128-137, 2014. 
FAO - Food and Agriculture Organization. Disponível em: http://faostat.fao.org/site/339/default.aspx. Acesso em: 20 mai. 2015.

FERREIRA, S.; CABRAL, M.; CRUZ, N. F. da; MARQUES, R. C. Economic and environmental impacts of the recycling system in Portugal. Journal of Cleaner Production. v. 79, p. 219-230, 2014.

GUO, R. LI, G.; JIANG, T.; SCHUCHARDT, F.; CHEN, T.; ZHAO, Y.; SHEN, Y. Effect of aeration rate, $\mathrm{C} / \mathrm{N}$ ratio and moisture on the stability and maturity of compost. Bioresource Tecnology. v. 112, p. 171-178, 2012.

JOLANUN, B.; TOWPRAYOON, S. Novel bulking agent from clay residue for food waste composting. Bioresource Technology. v. 101, p. 4484-4490, 2010.

KAPANEN, A.; VIKMAN, M.; RAJASARKKA, J.; VIRTA, M.; ITAVAARA, M. Biotests for environmental quality assessment of composted sewage sludge. Waste Management, v. 33, p. 1451-1460, 2013.

KAUSAR, H.; SAIRAH, M.; SAUD, H. M.; ALAM, M. Z.; ISMAIL, M. R. Isolation and screening of potential actinobacteria for rapid composting of rice straw. Biodegradation, v. 22, p. 367-375, 2011.

LI, Z.; LU, H.; HE, L. H. Experimental and modeling approaches for food waste composting: a review. Chemosphere, p. 1247-1257, 2013.

LUDUEÑA, L.; FASCE, D.; ALVAREZ, V. A.; STEFANI, P. M. Nanocellulose from rice husk following alkaline treatment to remove silica. Bioresources, v. 6, n. 2, p. 14401453,2011

NELSON, D. L.; COX, M. M. Princípios de Bioquímica de Lehninguer. Porto Alegre: Artmed, 2014. p. 1328.'

ROCA-PÉREZ, L.; MARTÍNEZ, C.; MARCILLA, P.; BOLUDA, R. Composting rice straw with sewage sludge and compost effects on the soil-plant system. Chemosphere, v. 75, p. 781-787, 2009. 
SHARMA, V. K. CANDITELLI, M. FORTUNA, F.; CORNACCHIA, G. Processing of urban and agro-industrial residues by aerobic composting: Review. Energy Convers. Mgmt., v.38, n. 5, p. 453-478, 1997.

VALVERDE, S.B.; REZENDE, J. L. P.; SILVA, M. L.; JACOVINE, L. A. G.; CARVALHO, R. M. M. A. Efeitos multiplicadores da economia florestal brasileira. Revista Árvore, v. 27, n. 3, p. 285-293, 2003.

YAÑES, R.; ALONSO, J. L.; DÍAS, M. J. Influence of bulking agente on sewage sludge composting process. Bioresource Technology, n. 100, p. 5827-5833, 2009.

ZHANG, F.; GU, W.; XU, P.; TANG, S.; XIE, K.; HUANG, X.; HUANG, Q. Effects o alkyl polyglycoside (APG) on composting of agricultural wastes. Waste Management, v. 31 , n. 6 , p. 1333-1338, 2011

ZHANG, L.; SUN, X. Influence of bulking agents on physical, chemical, and microbiological properties during the two-stage composting of green waste. Waste Management, n. 48, p. 155-126, 2016. 